\title{
Largest Issue of Journal of Materials Research Features Laser and Particle Beam Processing
}

The 1988 November/December issue of Journal of Materials Research is notably the largest JMR issue published in its remarkable three-year history. It contains nearly 400 pages of original research articles. Nearly half of this issue features articles on laser and particle beam processing of materials, an area of chemical and physical processes currently sparking great interest in interdisciplinary materials research.

Laser and particle beam processing has been the focus of numerous MRS symposia during the last 10 years and includes materials processing with ion, electron, and laser beams in different modes and systems. $J M R$ issued an invitation to authors to submit manuscripts on their new research results in this still-expanding field. More than 25 articles by researchers in prominent universities, laboratories, and corporations worldwide were eventually accepted for publication.

Processing methods, analysis techniques, and new materials properties discussed in these articles deal with ion beam mixing, ion implantation, laser annealing, ion bombardment, transmission electron microscopy, photochemical processing, physical vapor deposition, electron beam irradiation, and x-ray diffraction. Materials span intermetallic alloys, metals, elemental semiconductors, ceramics, thin films, and polymers. Overall, this special 200-page section of the 1988 November/December $J M R$ reflects the broad interdisciplinary aspects of materials research in the continually evolving field of laser and particle beam processing.

\section{High Temperature Superconductors and More}

The November/December issue's special section of laser and particle beam processing articles also echoes the success of the last year's November/December issue, which featured a group of articles on high temperature superconductors. Then, research on high temperature superconductors was just beginning to attract worldwide attention. Many of the research results published in the 1987 November/ December issue of JMR highlighted many important results in the high temperature superconductor arena. This field continues to expand rapidly, with tremendous competition among researchers. Several more articles on high temperature superconductors are published in this year's November/
December issue of $J M R$.

Other articles published in the November/December 1988 issue of $J M R$ feature materials such as metallic glasses, ceramics, intermetallic alloys, catalytic materials, optical materials, compound semiconductors, and polymers.

Joumal of Materials Research publishes original research articles, rapid communications, and reviews dealing with advanced materials preparation, processing, characterization, and properties. Subscribers number the 8,000 members of the Materials Research Society in addition to hundreds of prestigious technical libraries worldwide.

For information on article submission requirements for Joumal of Materials Research, contact Linda Krysinski, Editorial Office Supervisor, Journal of Materials Research, Materials Research Society, 9800 McKnight Road, Suite 327, Pittsburgh, PA 15237; telephone (412) 367-9111; fax (412) 367-4373.

For subscription information or a free sample copy, contact the Publications Department, Materials Research Society, 9800 McKnight Road, Suite 327, Pittsburgh, PA 15237; telephone (412) 367-3012; fax (412) $367-4373$.

\section{Candidates Sought for Graduate Student Awards at 1989 MRS Spring Meeting}

The Materials Research Society announces the availability of several awards for graduate students at the 1989 MRS Spring Meeting to be held April 24-29 in San Diego, California. Each award consists of a $\$ 250$ cash prize, payment of the registration fee for the 1989 Spring Meeting, and a certificate of achievement.

To qualify for a Graduate Student Award for the 1989 MRS Spring Meeting, the applicant must be a registered graduate student whose thesis research closely relates to one of the symposium topics at the meeting. The student must be an author or co-author of a symposium paper but need not be the presenter of the paper. MRS membership is not required, but the student must attend the meeting to receive the award.

Selection criteria include: outstanding performance in the conduct of the research, originality of the applicant's contributions, significant and timely research results, and the promise for substantial future achievement in materials research.

Required application materials include an application form obtainable from MRS headquarters, abstract of the paper to be presented at the meeting, and a letter of support from the research supervisor.

The deadline for applications to be received by MRS headquarters is February 1 , 1989. Obtain applications from the address below.

John B. Ballance

Executive Director

Materials Research Society

9800 McKnight Road, Suite 327

Pittsburgh, PA 15237

Telephone (412) 367-3003

Fax (412) 367-4373 